\title{
Did Tom Brady Save the US stock market? Market Anomaly or Market Efficiency?
}

\author{
Kofi A. Amoateng ${ }^{1}$ \\ ${ }^{1}$ School of Business, N. C. Central University, Durham, North Carolina, USA \\ Correspondence: Kofi A. Amoateng, School of Business, N.C. Central University, Durham, North Carolina, \\ 27713, USA. Tel: 1-919-530-7384. E-mail: amoateng@nccu.edu
}

Received: February 17, 2019

Accepted: April 23, 2019

Online Published: April 25, 2019

doi:10.5539/ijef.v11n5p128

URL: https://doi.org/10.5539/ijef.v11n5p128

\begin{abstract}
This study reexamines how the National Football conference (NFC) Super Bowl predictor influences investors' sentiment to affect U.S. stock market returns from 1967 to 2018. The overall empirical evidence significantly supports the NFC predictor-stock market relationship. Even continuous Super Bowl wins by Tom Brady's New England Patriots could not overturn the Super Bowl stock market predictor (SBSMP). The false positive evidence by the NFC Super Bowl continues to provide investors with extraordinary returns. While the evidence is positive, there is a need for more theoretical research on the SBSMP. The Super Bowl euphoria can create a multiplier effect on the winning team's local economy and overall stock market (Edmans et al., 2007) and (Palomino et al., 2009). This anomaly has demonstrated that an investor would have outperformed the market by using the Super bowl indicator. However, its predictive power is statistically declining but empirically significant (Thompson \& Sen, 2017).
\end{abstract}

Keywords: super Bowl, investor sentiment, stock market returns, market anomaly, and efficient market

\section{Introduction}

Ever since Leonard Koppett (1978) discovered the ironic and humorous correlation between Super Bowl winner and the US stock markets, there has been series of research on investors' sentiments and stock market returns. The accuracy of the Super Bowl to predict the stock markets in the United States according to Leonard Koppett would be a fluke chance. Many naïve investors fest the idea that Super Bowl winners can positively predict the stock market because of market anomalies. The new Super Bowl theory on the stock market demands an empirical reinvestigation. If the result of the Super Bowl is a clear predictor that has to some extent been influencing investors' behavior since its discovery in 1978, then the short-term reaction of the stock market to the Super Bowl will have been more pronounced after 1978 than it was before 1978 (Dyl \& Schatzberg, 1989).

The initial Super Bowl theory stated that when the winner of the Super Bowl was from the National Football conference (NFC) the stock markets would be higher than at the beginning of the year (Note 1). On the other hand, if the winner of the Super Bowl was from the American Football Conference (AFC) the stock market would be lower than at the beginning of the year (Note 2). This simple theory had held 65 percent of the time from 1967 to 1992 when NFC team won the Super Bowl game. Since the Super Bowl occurs within the first two months of the year, investors who wish to bet on this halo effect have lots of time to maximize on their bid-ask spread. The "NFC Super Bowl predictor" is a statistical oddity (Note 3). The stock market is over 85 percent dominated by institutional investors, and pension funds. About $5 \%$ to $10 \%$ is foreign investors and at least $5 \%$ who are individual investors have brokers so investor sentiment argument is relatively weak. There is, but a weak rationale for any sort of correlation between the Super Bowl's outcome and stock prices. The relationship where two variables correlate directly by chance is "false positive" (Ferson et al., 2003).

Krueger and Kennedy (1990) find that the Super Bowl Stock Market Predictor (SBSMP) correctly predicted the direction of five different market indices 20 times in the first 22 games (91\% accuracy). Further examination on SBSMP finds that the model no longer possesses abnormal predictive ability (Acherqui \& Born, 2015). In addition, they find the returns earned after the winner of the Super Bowl reduced and its ability to predict the direction of subsequent change in the S\&P500 and DJIA collapses to virtually zero since 1989. However, Thompson and Sen (2017) reconfirm that the predictive power of the Super Bowl indicator has waned since 1989. It is still a significant predictor whether the pre-game favorite wins or loses. 
On the other hand, the Super Bowl might boost the economic activity in the area where it will be held and boost the stocks of local companies (Payne et al., 2018). Such a correlation makes sense, and is far more likely to have true predictive power of moving forward. Another empirical investigation argues that the performance of local sports teams affects the safety, sentiment, and mood of the economy. Edmans et al. (2007) find that a comprehensive review of this literature documents a connection between sporting events and a wide range of mood variables, all the way from optimism, pessimism, and health to the specific number of homicides and suicides in a local economy. Furthermore, ample evidence shows that mood affects human behavior. Akerlof and Shiller (2009) find that mood affects economic decisions and may affect stock prices. Related explanations for this connection include mood-based changes in risk aversion (Kliger \& Levy, 2003) or investor misattribution (Lucey \& Dowling, 2005).

Lo (2007) argues that efficient market hypothesis (EMH) maintains that market prices fully reflect all available information. The EMH is the idea that a "random walk" is to characterize a price series where all subsequent price changes represent random departures from previous prices. It also means that if the flow of information is unimpeded and information is immediately reflected in stock prices, then tomorrow's price change will reflect only tomorrow's news and will be independent of the price changes today (Malkiel, 2003). Thus, patterns or irrationalities in the pricing of individual stocks that have been discovered in a search of historical experience, are unlikely to persist and will not provide investors with a method to obtain extraordinary returns.

Samuelson (1965) pioneered EMH by asserting that in an efficient market, price changes must be unforecastable if they are properly-anticipated, that is, if they fully incorporate the information and expectations of all market participants. After Samuelson's pioneer work, Fama (1965a; 1965b; 1970); (LeRoy, 1973); Rubinstein (1976); and Lucas (1978), EMH has been extended to incorporate non-tradable assets such as human capital, state-dependent preferences, heterogeneous investors, asymmetric information, and transaction costs. They all argue that individual investors form expectations rationally, markets aggregate information efficiently, and equilibrium prices incorporate all available information instantaneously. Departures of random walk hypothesis (RWH) employ different kinds of econometrics such as, Lo and MacKinlay (1988) variance ratios, and Fama and French (1988) serial correlation tests do not have sufficient empirical evidence to reject the EMH. Is the market efficient? Perhaps the most common challenge to the EMH is an anomaly, a regular pattern in an asset's return, which is reliable, widely known, and inexplicable (Note 4). The well-known anomalies, such as "size effect", January effect, and calendar effects of holiday, weekend, and turn-of-the-month seasonality seem to be a clear violation of the EMH. Most of these anomalies can be exploited by relatively simple trading strategies, and, while the resulting profits may not be riskless, they seem usually profitable relative to their risks (Lehmann, 1990) (Note 5). On other hand, EMH supporters might argue that such persistence is in fact evidence in favor of EMH and that these anomalies, cannot be exploited to any significant degree because of factors such as risk or transactions. In addition, some anomalies are currently inexplicable due to a lack of imagination on the part of academics, not necessarily a violation of the EMH.

The most long-lasting critique comes from psychologists and behavioral economists who assert that the EMH is based on counterfactual assumptions regarding human behavior that is rationality. Recent advances in evolutionary psychology and the cognitive neurosciences may be able to reconcile the EMH with behavioral anomalies. In light of the sociology of the EMH controversy, the debate is likely to continue (Lo, 2004). Despite the lack of consensus in academia and industry, the ongoing discourse has given us many new insights into the economic structure of financial markets. According to Paul Samuelson, if financial economics is the crown jewel of the social sciences, then the EMH must account for half the facets (Markowitz, 1991).

This study extends Dyl and Schatzberg (1989) study on the correlation between Super Bowl winner and the stock market returns spans from 1993 to 2018. Second, we look at the long span of data from 1967 to 2018 to find if the NFC Super Bowl predictor persists over time. Is the NFC Super Bowl predictor on the stock market a fluke chance? Again, is there any way in which investors can reliably exploit Super Bowl anomaly or patterns that may exist. In order words, can investors consistently cash in from the NFC Super Bowl predictor? Economists and psychologist in the field of behavioral finance find such short-run momentum to be consistent with psychological feedback mechanisms. Shiller (2000) describes the rise in the US stock market during the late 1990s as the result of psychological contagion leading to irrational exuberance. However, "contagion effects' are nor long-lasting. They come in one way and go out on another way. Another explanation for patterns of short-run momentum is a tendency for investors to either underreact or overreact to new information. To resolve the false positive puzzle of Super Bowl halo effect on the stock markets returns there is the need for theoretical foundation as to why a win by a particular team in the Super Bowl will boost investors sentiments to increase their stock holdings. Sports and U.S stock markets provide false positive evidence but the relationship lacks 
theoretical foundations on market timing for investors as to when to enter and exit the stock market (Wisniewski, 2016).

The rest of this study is as follows: Data and research methodology, and empirical results are in section 2 and 3, respectively. Discussions are in section 4.

\section{Data and Method}

In this section, we describe the variables and the sources of data used in the study. For clarity of exposition, the data are categorized into Super Bowl and few market fundamentals.

Table 1a. The super bowl and the US stock market subsample 1 (1967-1992)

\begin{tabular}{cccc}
\hline & Up Market & Down Market & Average return for S\&P500 \\
\hline All Years & 20 & 6 & $12.14 \%$ \\
NFC winning Years & 13 & 1 & $17.70 \%$ \\
AFC winning Years & 7 & 5 & $6.24 \%$ \\
\hline
\end{tabular}

Note $. \mathrm{n}=$ number of observations $=26$.

Table 1b. The super bowl and the US stock market subsample 2 (1993-2018)

\begin{tabular}{cccc}
\hline & Up Market & Down Market & Average return for S\&P500 \\
\hline All Years & 22 & 4 & $10.49 \%$ \\
NFC winning Years & 11 & 3 & $9.05 \%$ \\
AFC winning Years & 11 & 1 & $13.77 \%$ \\
\hline
\end{tabular}

Note. $\mathrm{n}=$ number of observations $=26$.

Table 1c. The super bowl and the US stock market full sample period (1967-2018)

\begin{tabular}{cccc}
\hline & Up Market & Down Market & Average return for S\&P500 \\
\hline All Years & 42 & 10 & $11.32 \%$ \\
NFC winning Years & 24 & 4 & $12.87 \%$ \\
AFC winning Years & 18 & 6 & $12.49 \%$ \\
\hline
\end{tabular}

Note. $\mathrm{n}=$ number of observations $=52$.

Tables $1 \mathrm{a}, 1 \mathrm{~b}$, and $1 \mathrm{c}$, provide statistics for quick reference. All series are at annual frequency. As a check of robustness, we perform the statistical analysis on the full sample and two equal subsamples. The first subsample period (1967-1992), includes the period when the NFC featuring Joe Montana's successive Super Bowl wins, dominated the Super Bowls. The second subsample (1993-2018), includes when the American Football Conference (AFC) featuring Tom Brady's successive Super Bowl wins, dominated the Super Bowls. The full sample contains 52 observations and spans from 1967-2018. Tables 1a,1b, and 1c present data regarding the outcome of the Super Bowl and the stock market's performance over 26 years. Using the S\&P500 as broadest indicator of the overall stock market, we measured annual returns from the close of the market on Friday, before the Super Bowl through the last trading day on the ninth month of the year (8 months after the Super Bowl is played). Both the NFC and AFC teams and the S\&P500 returns were collected from https://www.pro-football-reference.com/; www.ycharts.com and www.google.com.

Table1a (first subsample period of 1967-1992) shows the number of "up" versus "down" markets and the average market return for all the 26 years, NFC years and AFC years. The NFC won the Super Bowl in 13 of the 20 years with up markets, and the AFC won it in 5 of the 6 years with down markets. The contrast between the performance of the stock market in the years when the NFC won and its performance in those years when the AFC won was striking - a 17.70 percent increase for the former and only a 6.24 percent increase for the latter. In a slightly sharp contrast, Table 1b (the second subsample period of 1993-2018) shows the number of "up" versus "down" markets and the average return for all the 26 years, NFC years and AFC years. On the other side, the AFC won the Super bowl in 11 of the 22 years with up markets, and the NFC won it in 3, of the 4 years with down markets. The contrast between the performance of the stock market in the years when the AFC won and its performance in those years when the NFC won was slightly striking-a 13.77 percent increase for the former and only a 9.05 percent increase for the latter. The AFC Super Bowl anomaly supports the fact that the predictive power of the NFC Super Bowl indicator is waning over time. Nevertheless, Tom Brady's successive Super Bowl 
wins did not turn out to be significant increases in the stock markets. Table 1c (the full sample period of 1967-2018) shows the number of "up" versus "down" markets and the average market return for all the 52 years, NFC years and AFC years. In the long-run, the NFC won the Super Bowl in 24 years with up markets, and AFC won it 6 of the 10 years with down markets. The average market returns for both NFC Super Bowl winnings and AFC Super Bowl winnings are 12.87 percent, and 12.49 percent, respectively. Though the NFC Super Bowl wins exceeded the AFC Super Bowl wins by 6, their average market returns were about the same at 13 percent. It looked like both Joe Montana nor Tom Brady saved the US stock markets in the observed sample periods, but there was no rationale behind the positive evidence.

Table 2A. NFC predictor on S\&P500 returns 1967-2018

\begin{tabular}{|c|c|c|c|c|c|}
\hline Year & Team & Conference & S\&P return after 8months & Market (up/Down) & Correct \\
\hline 1967 & Green Bay & NFC & $11.38 \%$ & Up & Yes \\
\hline 1968 & Green Bay & NFC & $6.90 \%$ & Up & Yes \\
\hline 1969 & NY Jets & $\mathrm{AFC}$ & $-7.28 \%$ & Down & Yes \\
\hline 1970 & K.C Chiefs & $\mathrm{AFC}$ & $-7.89 \%$ & Down & Yes \\
\hline 1971 & Baltimore Colts & $\mathrm{AFC}$ & $6.36 \%$ & Up & No \\
\hline 1972 & D. Cowboys & NFC & $5.87 \%$ & Up & Yes \\
\hline 1973 & Miami Dolphins & $\mathrm{AFC}$ & $-11.24 \%$ & Down & Yes \\
\hline 1974 & Miami Dolphins & $\mathrm{AFC}$ & $-32.71 \%$ & Down & Yes \\
\hline 1975 & Pitt Steelers & NFC & 16.56 & Up & Yes \\
\hline 1976 & Pitt Steelers & NFC & $8.68 \%$ & Up & Yes \\
\hline 1977 & Oak. Raiders & $\mathrm{AFC}$ & $-7.47 \%$ & Down & Yes \\
\hline 1978 & D. Cowboys & NFC & $14.54 \%$ & Up & Yes \\
\hline 1979 & Pitt Steelers & NFC & $8.75 \%$ & Up & Yes \\
\hline 1980 & Pitt Steelers & NFC & $14.18 \%$ & Up & Yes \\
\hline 1981 & Oak Raiders & $\mathrm{AFC}$ & $-11.12 \%$ & Down & Yes \\
\hline 1982 & S F 49ers & NFC & $5.25 \%$ & Up & Yes \\
\hline 1983 & Redskins & NFC & $15.05 \%$ & Up & Yes \\
\hline 1984 & LA Raiders & $\mathrm{AFC}$ & $0.38 \%$ & Up & No \\
\hline 1985 & S F 49ers & NFC & $7.30 \%$ & Up & Yes \\
\hline 1986 & Chicago Bears & NFC & $13.96 \%$ & Up & Yes \\
\hline 1987 & NY Giants & NFC & $19.29 \%$ & Up & Yes \\
\hline 1988 & Redskins & NFC & $7.07 \%$ & Up & Yes \\
\hline 1989 & S F 49ers & NFC & $19.97 \%$ & Up & Yes \\
\hline 1990 & S F 49ers & NFC & $-6.87 \%$ & Down & No \\
\hline 1991 & NY Giants & NFC & $18.05 \%$ & Up & Yes \\
\hline 1992 & Redskins & NFC & $0.63 \%$ & Up & Yes \\
\hline Final outcome & & & $\overline{\mathrm{r}}=3.41 \%$ & Up market $=73 \%$ & Yes $=89 \%$ \\
\hline
\end{tabular}

Note. American Football Conference (AFC) teams are: Baltimore Ravens, Buffalo Bills, Cincinnati Bengals, Cleveland Browns, Denver Broncos, Houston Texans, Indianapolis Colts, Jacksonville Jaguars, Kansas City Chiefs, Los Angeles Chargers, Miami Dolphins, New England Patriots, New York Jets, Oakland Raiders, Pittsburg Steelers, and Tennessee Titans.

National Football Conference (NFC) teams are: Arizona Cardinals, Atlanta Falcons, Carolina Panthers, Chicago Bears, Dallas Cowboys, Detroit Lions, Green Bay, Los Angeles Rams, Minnesota Vikings, New Orleans Saints, New York Giants, Philadelphia Eagles, San Francisco 49ers, Seattle Seahawks, Tampa Bay Buccaneers, and Washington Redskins.

Table 2B. NFC predictor on S\&P500 returns 1967-2018

\begin{tabular}{llllll}
\hline Year & Team & Conference & S\&P return after 8months & Market (up/Down) & Correct \\
\hline 1993 & D. Cowboys & NFC & $5.43 \%$ & Up & Yes \\
1994 & D. Cowboys & NFC & $1.15 \%$ & Up & Yes \\
1995 & S. F. 49ers & NFC & 22.17 & Up & Yes \\
1996 & D. Cowboys & NFC & $9.70 \%$ & Up & Yes \\
1997 & Green Bay & NFC & 20.95 & up & Yes \\
1998 & D. Broncos & AFC & $6.64 \%$ & Up & No \\
1999 & D. Broncos & AFC & $5.71 \%$ & Up & No \\
2000 & St. Louis Rams & NFC & $3.15 \%$ & Up & Yes \\
\hline
\end{tabular}




\begin{tabular}{|c|c|c|c|c|c|}
\hline 2001 & B. Ravens & $\mathrm{AFC}$ & $-23.09 \%$ & Down & Yes \\
\hline 2002 & Patriots & $\mathrm{AFC}$ & $-26.05 \%$ & Down & Yes \\
\hline 2003 & Buccaneers & NFC & $13.61 \%$ & Up & Yes \\
\hline 2004 & Patriots & $\mathrm{AFC}$ & $-1.15 \%$ & Down & Yes \\
\hline 2005 & Patriots & $\mathrm{AFC}$ & $3.79 \%$ & $\mathrm{Up}$ & No \\
\hline 2006 & Pitt Steelers & NFC & $3.11 \%$ & Up & Yes \\
\hline 2007 & Ind. Colts & $\mathrm{AFC}$ & $5.31 \%$ & Up & No \\
\hline 2008 & NY Giants & NFC & -11.87 & Down & No \\
\hline 2009 & Pitt Steelers & NFC & $20.49 \%$ & Up & Yes \\
\hline 2010 & Saints & NFC & 0.475 & Up & Yes \\
\hline 2011 & Packers & NFC & $-8.06 \%$ & Down & No \\
\hline 2012 & NY Giants & NFC & $10.73 \%$ & Up & Yes \\
\hline 2013 & B. Ravens & $\mathrm{AFC}$ & 13.29 & Up & No \\
\hline 2014 & Seattle Seahawk & NFC & $9.09 \%$ & Up & Yes \\
\hline 2015 & Patriots & $\mathrm{AFC}$ & $-4.03 \%$ & Down & Yes \\
\hline 2016 & D. Broncos & $\mathrm{AFC}$ & $12.02 \%$ & $\mathrm{Up}$ & No \\
\hline 2017 & Patriots & $\mathrm{AFC}$ & $8.01 \%$ & Up & No \\
\hline 2018 & Philly Eagles & NFC & $4.07 \%$ & Up & Yes \\
\hline Final outcome & & & $\overline{\mathrm{r}}=4.02 \%$ & Up market $=77 \%$ & Yes $=65 \%$ \\
\hline
\end{tabular}

Tables 2A and 2B report the two major divisions of the U.S. football competition (AFC/NFC) and their corresponding stock market returns, 8 months after their Super Bowl victory. It is argued that 11 months after the Super Bowl victory is relatively too long to make significant impact on the stock markets. In table $2 \mathrm{~A}$, the NFC Super Bowl predictor was about $89 \%$ correct, the market was up for about $73 \%$, and mean return was $3.4 \%$ in the observed period. In table 2B, the NFC Super Bowl predictor was only $65 \%$ correct, but the market was up for about $77 \%$ and the mean in the observed period rose to $4.02 \%$. The full sample period was not significantly different from the two subsamples. While the NFC Super Bowl predictor was $77 \%$, the market was up for about $75 \%$ and a mean return of $3.72 \%$. Overall, the NFC predicator Super Bowl is losing steam but it is about $77 \%$ correct and the up market is also about 75\%. Now, both winnings by NFCs and AFCs in the two sample periods influence the behavior of investors and consequently on the stock market. The NFC won in 2014 and the market went up. In 2015, the Patriots of the AFC won and the market went up just 1.36\%. A hypothetical portfolio of 4 assets randomly selected from leading fortune 500 companies in the East and West will attempt to explain the rationale behind the NFC Super Bowl predictor and the evidence in 2014 and 2015. The assets from the West (Amazon Inc and Apple Inc) outperformed those from the East (GE and Pfizer) in both long/short sales from 2001 to 2018. They also outperformed the S\&P 500 index in the period observed. It is to be noted that the long-short investing is fundamentally different from conventional investing in some important perspectives. Long-short portfolios differ fundamentally from long-only portfolios in construction, in the measurement of their risk and return, and in their implementation costs (Jacobs et al., 1996). The rationale behind this significant evidence is that the West, particularly the San Francisco Bay area is endowed with diversified industries from aerospace, biotechnology, education, electronics, entertainment, food and drink, media, real estate software, sports, to transportation and logistics. In a sharp contrast, the East, particularly New England area is equally endowed with industries from apparel, electrical, financial, insurance, to pharmaceuticals and many are aging companies, such as General electric and Pfizer. Boosting local economy influences investor sentiment and consequently impact the overall stock markets. Thus, the Super Bowl euphoria can create multiplier effect on the winning team's local economy and the overall stock markets (Edmans et al., 2007) and (Palomino et al., 2009). 
Table 3. NFC-win Long sales

Hypothetical Portfolio of 4 assets

AFC-win Short Sales

\begin{tabular}{|c|c|c|c|c|c|c|c|c|c|c|}
\hline Date & Amazon & Apple & GE & Pfizer & S\&P500 & SWin & Amazon & Apple & GE & Pfizer \\
\hline 2001 & & & & & -11.89 & $\mathrm{AFC}$ & -30.47 & -71.06 & -7.071 & 41.81 \\
\hline 2002 & & & & & -22.10 & $\mathrm{AFC}$ & 74.58 & 47.23 & -16.39 & -13.37 \\
\hline 2003 & 178.6 & 49.13 & 27.23 & 15.57 & 28.68 & NFC & & & & \\
\hline 2004 & & & & & 10.88 & $\mathrm{AFC}$ & -15.83 & 201.36 & 17.82 & -23.89 \\
\hline 2005 & & & & & 4.91 & $\mathrm{AFC}$ & 6.46 & 123.3 & -3.97 & -13.28 \\
\hline 2006 & -16.31 & 18.01 & 6.16 & 11.06 & 15.79 & NFC & & & & \\
\hline 2007 & & & & & 5.49 & $\mathrm{AFC}$ & 134.8 & 133.5 & -0.38 & -12.24 \\
\hline 2008 & -44.65 & -56.91 & -56.30 & -22.09 & -37 & NFC & & & & \\
\hline 2009 & 162.3 & 146.9 & -6.60 & 2.71 & 26.46 & NFC & & & & \\
\hline 2010 & 33.81 & 53.07 & 20.89 & -3.74 & 15.06 & NFC & & & & \\
\hline 2011 & -3.83 & 25.56 & -2.08 & 23.59 & 2.11 & NFC & & & & \\
\hline 2012 & 44.93 & 31.40 & 17.20 & 15.90 & 16 & NFC & & & & \\
\hline 2013 & & & & & 32.39 & $\mathrm{AFC}$ & 58.96 & 5.42 & 33.54 & 22.13 \\
\hline 2014 & -22.18 & 37.72 & -9.85 & 1.70 & 13.69 & NFC & & & & \\
\hline 2015 & & & & & 1.38 & $\mathrm{AFC}$ & 117.8 & -4.64 & 23.27 & 3.63 \\
\hline 2016 & & & & & 11.96 & $\mathrm{AFC}$ & 10.95 & 10.03 & 1.44 & 0.62 \\
\hline 2017 & & & & & 21.83 & AFC & 55.96 & 46.11 & -44.78 & 11.51 \\
\hline 2018 & 28.43 & -6.79 & -56.62 & 20.51 & -4.38 & NFC & & & & \\
\hline Cumu effect & +361.1 & +260.4 & -55.75 & +65.21 & +129.3 & & +357.3 & +495.5 & +3.44 & +16.92 \\
\hline
\end{tabular}

Note. Sample period=18 years (2001 -2018), SWin=Super Bowl Champion NFC/AFC

Cumu effect=Cumulative effect.

Portfolio is made of 4 assets from West, San Francisco Bay and Area, East, Boston and New York. The hypothetical portfolio includes 2 from the East- GE and Pfizer, and two from the West and Bay area are Apple Inc and Amazon Inc.

The East, New York, Boston and New England have aging companies such as General Electric (GE), Insurance companies and Pharmaceuticals such as Pfizer.

The West, Seattle, San Francisco Bay Area have many Fortune 500 companies and diversified industries in Aerospace; Apparel; Automotive; Consumer goods; Creative/design, Education, Electronics, Engineering and Construction, Entertainment, Financial, food and drink, Healthcare, Internet, Media. Mobile media, Musical instruction and accessories, Networking, Real estate, Retail, Sports, Telecommunications and transportation and logistics.

In 2016 and 2017 Tom Brady's New England Patriots (AFC team) won the Super Bowl consecutively and market went up by $11.96 \%$ and $21.83 \%$, respectively. In 2018, a NFC team (Philadelphia Eagles) won the Super Bowl and the market went down by $-6.24 \%$, reducing the power of the NFC Super Bowl predictor. In 2019, Tom Brady's team the New England Patriots (AFC team) won the Super Bowl but this could hurt the stock market if the NFC Super Bowl predictor turned out to be correct.

Maybe, probability could be used to estimate the chance of the association of NFC wins and up markets. Assuming we have two "urns", one labeled "Super Bowl" and one labeled "stock market." In subsample period 1967-1992, the Super Bowl urn contains 20 white balls denoting NFC wins and 6 red ball denoting AFC wins. The stock market also contains 15 white balls, denoting up markets and 7 red balls denoting down markets. Therefore, the probability that the draw from the Super Bowl urn will be the same as the draw from the stock market urn, for a single pair is 64.50 percent (Greene, 2012) (Note 6). $\div$

Now, as we observe the Super Bowl/Stock Market relationship in 24 in the last 26 years of the subsample 1, we are interested in the probability of 24 or more of these matches occurring over 26 draws. Using the binomial model, we find that this probability is 0.1272 percent, or roughly one chance out of 786 (Note 7). Therefore, a mere chance is probably the best explanation of the Super Bowl/stock market puzzle. The odds against it are impressive. When faced with a seemingly inexplicable phenomenon, financial economists generally attempt to make up sophisticated stories that might account for its occurrence. Such stories are riddled, with complex mathematical models that are not realistic. The funny thing is that with all the sophisticated models at our disposal, we cannot even forecast tomorrow's stock price accurately. 
Table 4a. Summary statistics S\&P500, market fundamentals, and Super Bowl Dummy 1967-1992

\begin{tabular}{llllll}
\hline Variable & Observations & Mean & Standard Deviation & Minimum & Maximum \\
\hline S\&P500 & 26 & 4.44 & 12.27 & -32.71 & 19.97 \\
GDP $_{\mathrm{t}-1}$ & 26 & 3.08 & 2.43 & -2.56 & 6.90 \\
T-Bill & 26 & 7.11 & 2.49 & 2.91 & 14.70 \\
SuperBDum & 26 & 4.45 & 12.12 & -32.71 & 19.97. \\
\hline
\end{tabular}

Note. $\mathrm{S} \& \mathrm{P} 500=$ average $\mathrm{S} \& \mathrm{P} 500$ returns, $\mathrm{GDP}_{\mathrm{t}-1}=$ previous gross domestic product growth rates, T-Bill=three-month U.S Treasury bill rates, and SuperDum $=$ Super Bowl Dummy, NFC win $=1$, and AFC win $=0$.

Table 4b. Summary Statistics S\&P500, market fundamentals, and Super Bowl Dummy 1993-2018

\begin{tabular}{llllll}
\hline Variable & Observations & Mean & Standard Deviation & Minimum & Maximum \\
\hline S\&P500 & 26 & 4.02 & 11.68 & -26.05 & 22.17 \\
GDP growth & 26 & 2.55 & 1.66 & -3.05 & 4.72 \\
T-Bill & 26 & 2.39 & 2.09 & 0.01 & 6.00 \\
SuperBDum & 26 & 2.52 & 10.85 & -26.05 & 22.17 \\
\hline
\end{tabular}

Note. see $4 \mathrm{a}$.

Table 4c. Summary Statistics S\&P500, market fundamentals, and Super Bowl Dummy 1967-2018

\begin{tabular}{llllll}
\hline Variable & Observations & Mean & Standard Deviation & Minimum & Maximum \\
\hline S\&P500 & 52 & 4.23 & 11.87 & -32.71 & 22.17 \\
GDP growth & 52 & 2.81 & 2.08 & -3.05 & 6.90 \\
T-Bill & 52 & 4.75 & 3.29 & 0.01 & 14.70 \\
SuperBDum & 52 & 3.49 & 11.43 & -32.71 & 22.17 \\
\hline
\end{tabular}

Note. see $4 \mathrm{a}$.

Tables $4 \mathrm{a}$ to $4 \mathrm{c}$ report one consistent pattern, and that the S\&P500 has the highest mean and standard deviation in the series and in all sample periods. Strikingly, the highest mean (12.14\%) is recorded in the Subsample 1 and the relatively highest standard (17.33\%) is also recorded in the Subsample 2. The full sample consistently follows both samples. The conditioning variables (control variables) - previous gross domestic product growth rates; three-month Treasury bill rates are collected from www.ycharts.com and www.google.com. To model the Super Bowl objective, we define the following Super Bowl winning dummy variables:

- $\quad \mathrm{NFCD}_{\mathrm{t}}=1$ if a NFC team wins at time $\mathrm{t} ; \mathrm{NFCD}_{\mathrm{t}}=0$ otherwise.

The Super Bowl winning index variable that we employed is motivated by the Super Bowl/stock market phenomenon reported in the sports column of the New York Times in 1978 by Leonard Koppett, and subsequent article in the Guest Speaker of Financial Analysts Journal by (Dyl \& Schatzberg, 1989). To measure the correlation between the expected stock returns, the conditioning variables, and the effects on Super Bowl we run the following regression (Note 7):

$$
\dot{R}_{t+1}=\beta_{0}+\beta_{1} \text { Tbill }_{t}+\beta_{2} G D P_{t-1}+\beta_{3} \text { SuperDum }_{t}+u_{t+1}
$$

Where; $\dot{R}_{t+1}$ is the expected annual S\&P500 stock returns; $\beta_{0}$ is the intercepts, $\beta_{1}, \ldots, \beta_{2}$ are the unknown parameters, which measure the impact of the conditioning variables on the stock market returns, $\beta_{3}$ is a parameter, which measures the influence of the Super Bowl on the stock market returns, and $\mathrm{u}_{\mathrm{t}+1}$, is stochastic disturbance terms, which describes all the conditioning variables, plus noise that is not directly related to the pre-specified variables.

\section{Empirical Results}

Table 5a. Estimated results of the NFC indicator, market fundamentals and stock market 1967-1992

\begin{tabular}{llllll}
\hline$\dot{\mathrm{R}}_{\mathrm{t}+1}=\beta_{0}+\beta_{1}$ Tbill $_{\mathrm{t}}+\beta_{2} \mathrm{GDP}_{\mathrm{t}-1}+\beta_{3}$ SuperDum $_{\mathrm{t}}+\mathrm{u}_{\mathrm{t}+1}$ & & & & \\
\hline Intercept & $\mathrm{TBill}$ & $\mathrm{GDP}$ & SuperBDum & Adjusted $\mathrm{R}^{2}$ & D.W \\
\hline 0.55 & 0.07 & -0.11 & 0.99 & 0.97 & 2.06 \\
$(0.41)$ & $(0.40)$ & $(-0.65)$ & $(29.96)^{\mathrm{a}}$ & & \\
\hline
\end{tabular}

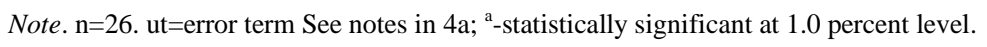


Table 5b. Estimated results of the NFC indicator, market fundamentals and stock market 1993-2018

\begin{tabular}{llllll}
\hline$\dot{\mathrm{R}}_{\mathrm{t}+1}=\beta_{0}+\beta_{1}$ Tbill $_{\mathrm{t}}+\beta_{2} \mathrm{GDP}_{\mathrm{t}-1}+\beta_{3}$ SuperDum $_{\mathrm{t}}+\mathrm{u}_{\mathrm{t}+1}$ & & & \\
\hline Intercept & $\mathrm{TBill}$ & $\mathrm{GDP}$ & SuperBDum & Adjusted $\mathrm{R}^{2}$ & D.W \\
\hline 0.02 & 0.92 & -0.33 & 0.97 & 0.79 & 2.12 \\
$(0.03)$ & $(1.21)$ & $(-0.54)$ & $(9.77)^{\mathrm{a}}$ & & \\
\hline
\end{tabular}

Note. ${ }^{\text {a }}$-statistically significant at 1.0 percent level. See notes in 4 a.

Table 5c. Estimated results of the NFC indicator, market fundamentals and stock market 1967-2018

\begin{tabular}{llllll}
\hline$\dot{\mathrm{R}}_{\mathrm{t}+1}=\beta_{0}+\beta_{1}$ Tbill $_{\mathrm{t}}+\beta_{2} \mathrm{GDP}_{\mathrm{t}-1}+\beta_{3}$ SuperDum $_{\mathrm{t}}+\mathrm{u}_{\mathrm{t}+1}$ & & & \\
\hline Intercept & $\mathrm{TBill}$ & GDP & SuperBDum & Adjusted $\mathrm{R}^{2}$ & D.W \\
\hline 1.06 & 0.30 & -0.23 & 0.98 & 0.89 & 1.94 \\
$(0.93)$ & $(1.10)$ & $(-1.32)$ & $(20.21)^{\mathrm{a}}$ & & \\
\hline
\end{tabular}

Note. ${ }^{\text {a }}$-statistically significant at 1.0 percent level. See notes in 4 a.

The main point here is that all the tables tell the same story and that the NFC Super Bowl predictor significantly explains the stock market returns by over $80 \%$ in all the sample periods. The NFC Super Bowl predictor is positively significant with the stock market returns at 1.0percent level in all sample periods. Our results do not suffer from auto correlation and multicollinearity problem (Note 8). The study performs three robustness tests to bolster the findings. First, a sample size of 13 is tested and the results are not statistically different from Subsample 1 (Note 9). The next robustness test uses a sample size of 14 and the results support the finding in subsample 2 (Note 10). Finally, the robustness test uses a sample size of 28 and the results are not statistically different from the full sample (Note 11). Therefore, the overall empirical evidence significantly supports the NFC predictor-stock market relationship. However, its predictive power is Statistically declining.

\section{Discussions}

The purpose of this study is to reexamine how macroeconomic variables and non-economic variable (Super Bowl dummy) influence investor sentiments to affect stock returns of during 1967 to 2018 period. The most consistent finding is that the NFC Super Bowl predictor significantly explains the stock market at the 1.0 percent level. Dyl and Schtzberg (1989), and Krueger and Kennedy (1990) lend support to the NFC Super Bowl predictor. The predictor also significantly explains the stock market in the subsample 2 and full sample at the 1.0 percent level of significance. However, its predictive power is statistically declining but empirically significant.

The statistical and empirical evidence is positive but the rationale is still questionable. While the evidence is positive, there is a need for more theoretical research on the Super Bowl -Stock market relationship. However, the false positive evidence in this study is unlikely to persist and will not provide a long-lasting extraordinary returns for investors. Therefore, Tom Brady's successive Super Bowl wins did not turn out to be significant increases in the stock markets. The rationale behind this significant evidence is that the West, particularly the San Francisco Bay area is endowed with diversified industries from aerospace, biotechnology, education, electronics, entertainment, food and drink, media, real estate software, sports, to transportation and logistics. In sharp contrast, the East, particularly New England area is equally endowed with industries from apparel, electrical, financial, insurance, to pharmaceuticals and many are aging companies, such as General electric and Pfizer. Boosting local economy influences investor sentiment and consequently impact the overall stock markets. Thus, the Super Bowl euphoria can create multiplier effect on the winning team's local economy and the overall stock markets (Edmans et al., 2007) and (Palomino et al., 2009). Therefore, the overall empirical evidence significantly supports the NFC predictor-stock market relationship.

With the booming technology industry in San Francisco Bay area, businesses face stress test to keep up with the surge of new companies in the 1990s. Companies formerly based in the San Francisco Bay area that had relocated their headquarters from the Bay area to elsewhere include the following, Bank of America to Charlotte, North Carolina, Bechtel to Reston, Virginia, Caterpillar Inc to Peoria, Illinois, to mention but few. Nearly 40 companies are either defunct or relocated to other states or another country in the 1990s and 2000s. Some areas, such Reston, Virginia, and Charlotte, North Carolina that were not previously endowed with resources and industries are now experiencing diversified industries. Changing fortunes of states and areas from time to time may potentially affect the accuracy of the NFC Super Bowl predictor. Since probability is involved, the NFC Super Bowl predictor anomaly may not predict the stock market consistently over time. 


\section{References}

Acherqui, Y., \& Born, J. A. (2015). A symmetric Super Bowl Stock Market Predictor. Financial Markets and Portfolio Management, 10(29), 115-124.

Akerlo, G., \& Shiller, R. (2009). Animal spirits: How human psychology drives the economy, and why it matters for global capitalism. Princeton. NJ: Princeton University Press.

Bernhard, W., \& Leblang, D. (2000). Democratic processes, Political risk and foreign exchange markets. American Journal of Political Science, 46(2), 316-33.

Blanchard, O., \& Perotti, R. (2000). An empirical characterization of the dynamic effects of changes in government spending and taxes on output. NBER Working Paper No. 7269.

Celis, E. E., \& Shen, L. J. (2015). Political cycle and stock market: The case of Malaysi. Journal of Emerging Issues in Economics and Banking, 4(1), 1461-1512.

Dyl, A. E., \& Schatzberg, D. J. (1989). Did Joe Montana save the Stock Market? Financial Analysts Journal, (September/October), 4-5.

Edmans, A., Garcia, D., \& Norli, O. (2007). Sports sentiment and stock returns. Journal of Finance, 62, 1967-1997.

Fama, E. (1965a). The behavior of stock market prices. Journal of Business, 38, 34-105.

Fama, E. (1965b). Random walks in stock market prices. Financial Analysts Journal, 21, 55-59.

Fama, E. (1970). Efficient capital markets: A review of theory and empirical work. Journal of Finance, 25, 383-417.

Fama, E., \& French, K. (1988). Permanent and temporary components of stock prices. Journal of Political Economy, 96, 246-273.

Ferson, W. E., Sarkissian, S., \& Smith, T. T. (2003). Spurious regression in financial economics. Journal of Finance, 58, 41-45.

Greene, H. W. (2012). Econometric Analysis (7th ed.). Upper Saddle River, New Jersey: Pearson.

Jacobs, B. I., \& Levy, K. N. (1996). 20 Myths about Long-Short. Financial Analysts Journal, (September/October), 81-85.

Kliger, D., \& Levy, O. (2003). Mood-induced variation in risk preferences. Journal of Economic Behavior and Organization, 52, 573-584.

Krueger, M. T., \& Kennedy, F. W. (1990). An examination of the Super Bowl Stock Market Predictor. Journal of Finance, (June, 1990), 691-697.

Lehmann, B. (1990). Fads, martingales, and market efficiency. Quarterly Journal of Economics, 105, 1-28.

LeRoy, S. (1973). Risk aversion and martingale property of stock returns. International Economics Review, 14, 436-446.

Lo, W. A. (2004). The adaptive markets hypothesis: market efficiency from an evolutionary perspective. Journal of Portfolio Management, 30, 15-29.

Lo, W. A. (2007). Efficient market hypothesis. In L. Blume \& S. Durlauf (Eds.), The New Palgrave: A Dictionary of Economics (2nd ed.). New York: Palgrave McMillan.

Lo, A., \& MacKinlay, C. (1988). Stock market prices do not follow random walks: Evidence from a simple specification test. Review of Financial Studies, 1, 41-66.

Lucas, R. (1978). Asset prices in an exchange economy. Econometrica, 46, 1429-1446.

Lucey, B., \& Dowlling, M. (2005). The role of feelings in investor decision-making. Journal of Economic Surveys, 19, 211-237.

Malkiel, G. B. (2003). The efficient market hypothesis and its critics. Journal of Economic Perspectives, 17, 59-82.

Markowitz, H. (1991). Foundations of portfolio theory. Journal of Finance, 46, 469-477.

Palomino, F., Renneboog, L., \& Zhang, C. (2009). Information salience, investor sentiment and stock returns: The case of British soccer betting. Journal of Corporate Finance, 15, 368-387. 
Payne, B. C., Tresl, J., \& Friesen, G. C. (2018). Sentiment and stock returns: Anticipating major event. Journal of Sports Economics, 1-30.

Rubinstein, M. (1976). The valuation of uncertain streams and the pricing of options. Bell Journal of Economics, 7, 407-425.

Samuelson, P. (1965). Proof that properly anticipated prices fluctuate randomly. Industrial Management Review, $6,41-49$.

Santa-Clara, P., \& Valkanov, R. (2003). The presidential puzzle: Political cycles and the stock market. Journal of Finance, 58(5), 1841-1872.

Shiller, J. R. (2000). Irrational Exuberance Princeton. Princeton University Press.

Tavares, J., \& Valkanov, R. (2001). The neglected effect of fiscal policy on stock and bond returns. Working Paper, Anderson School of Management, University of California, Los Angeles.

Thompson, H. T., \& Sen, C. K. (2018). Exploring a market curiosity: An examination of the Super Bowl Indicator. Managerial Finance, 43(2), 167-177.

Wisniewski, T. P. (2016). Is there a link between politics and stock return? A literature survey. International Review of Financial Analysis, Forthcoming, 1.

\section{Notes}

Note 1. This is the list of the teams belonging to the National Football conference (NFC):

NFC (East) $\rightarrow$ Dallas Cowboys; New York Giants; Philadelphia Eagles; and Washington Redskins.

NFC (North) $\rightarrow$ Chicago Bears; Detroit Lions; Green Bay Packers; and Minnesota Vikings.

NFC (South) $\rightarrow$ Atlanta Falcons; Carolina Panthers; New Orleans Saints; and Tampa Bay Buccaneers.

NFC (West) $\rightarrow$ Arizona Cardinals; Los Angeles Rams; San Francisco 49ers, and Seattle Seahawks.

Note 2. This is the list of the teams belonging to the American Football conference:

AFC (East) $\rightarrow$ Buffalo Bills; Miami Dolphins; New England Patriot; and New York Jets.

AFC (North) $\rightarrow$ Baltimore Ravens; Cincinnati Bengals; Cleveland Browns; and Pittsburg Steelers.

AFC (South) $\rightarrow$ Houston Texans; Indianapolis Colts; Jacksonville Jaguars, and Tennessee Titans

AFC (West) $\rightarrow$ Denver Broncos; Kansas City Chiefs; Los Angeles Chargers; and Oakland Raiders.

Note 3. The Super Bowl is the final game in the National Football league's season and occurs usually in February. The champion, is crowned as a result of this single game, adding to the excitement. Unlike many sports Leagues around the world, the NFL uses two separate bracket systems. The champions of the two conferences, the AFC and NFC, meet in the Super Bowl, which means that if the two best teams in the entire league happen to be in the same conference, only one of them will get the bid to the Super Bowl, which is held in a different city every year.

Note 4. The fact that the pattern is regular and reliable implies a degree of predictability, and the fact that the regularity is widely known implies that many investors can take advantage of it.

Note 5. In probability theory, a martingale is a sequence of random variables (i.e., a stochastic process) for which, at a particular time, the conditional expectation of the next value in the sequence, given all prior values, is equal to the present value.

Note 6. Probability $=P=p(W, W)+p(R, R)$

$$
\begin{aligned}
& =(20 / 26)(20 / 26)+(6 / 26(6 / 26) \\
& =0.7692 \times 0.7692 \quad+0.2308 \times 0.2308 \\
& =0.5917+0.0533 \quad=\underline{\mathbf{0 . 6 4 5 0}}
\end{aligned}
$$

Note 7. We use EXCEL to compute the following $=\operatorname{BINOMDIST}(24,26,0.645$, (FALSE) $=0.0001109642$

$$
\begin{aligned}
& =\text { BINOMDIST }(25,26,0.645,(\text { FALSE })=0.000160027 \\
& =\text { BINOMDIST }(26,26,0.645,(\text { FALSE })=0.000011829 \\
& =\underline{\mathbf{0 . 0 0 1 2 7 2 2}}
\end{aligned}
$$


We can use the Bernoulli distribution for a single binomial outcome (trial).

$$
\begin{gathered}
\operatorname{Prob}(\mathrm{x}=1)=\alpha, \\
\operatorname{Prob}(\mathrm{x}=0)=1-\alpha,
\end{gathered}
$$

Where $0 \leq \alpha \leq 1$. The modeling aspect of this specification would be the assumptions that the success probability $\alpha$ is constant from one trial to the next and that successive trials are independent. If so, then the distribution for $\mathrm{x}$ successes in $\mathrm{n}$ trials is the binomial distribution,

$$
\operatorname{Prob}(\mathrm{X}=\mathrm{x})=\left({ }_{\mathrm{x}}{ }^{\mathrm{n}}\right) \alpha^{\mathrm{x}}(1-\alpha)^{\mathrm{n}-\mathrm{x}}, \mathrm{x}=0,1, \ldots \mathrm{n} .(\text { Greene, 2012). }
$$

Note 8 . The results of the Durbin-Watson test and Pearson correlation matrix test shows that the data were not measured with errors, and the independent variables were not explaining themselves instead of the dependent variable, respectively.

\section{Robustness: Sample 1 (1967-1992).}

Note 9. $\overline{\mathrm{R}}=-2.59+0.13 \mathrm{GDP}+0.14 \mathrm{TBill}+1.08$ SuperBDum + ut
$(-1.14)$
$(0.61) \quad(0.59)$
$(15.02)^{\mathrm{a}}$
Adjusted $\mathrm{R}^{2}=0.96, \mathrm{DW}=1.84 \mathrm{~N}=13$

Robustness: Sample 2 (1993-2018).

Note 10. $\overrightarrow{\mathrm{R}}=-3.33+0.63 \mathrm{GDP}+0.68 \mathrm{TBill}+0.99$ SuperBDum + ut
$(-1.83)$
(0.97)
$(1.08)$
$(11.56)^{\mathrm{a}}$
Adjusted $\mathrm{R}^{2}=0.90 \mathrm{DW}=2.19 \mathrm{~N}=14$

Note 11. Robustness: Full Sample (1967-2018)

$$
\begin{aligned}
& \overline{\mathrm{R}}=0.25+0.26 \mathrm{GDP}-0.13 \mathrm{TBill}+0.97 \text { SuperBDum }+ \text { ut } \\
& \text { (0.20) (1.15) (-0.78) (25.15) })^{\mathrm{a}} \quad \text { Adjusted } \mathrm{R}^{2}=0.97 \quad \mathrm{Dw}=1.75 \mathrm{~N}=28 \text {. }
\end{aligned}
$$

\section{Copyrights}

Copyright for this article is retained by the author(s), with first publication rights granted to the journal.

This is an open-access article distributed under the terms and conditions of the Creative Commons Attribution license (http://creativecommons.org/licenses/by/4.0/). 